\title{
Engineered Metalloenzymes with Non-Canonical Coordination Environments
}

DOI:

10.1002/chem.201800975

\section{Document Version}

Accepted author manuscript

Link to publication record in Manchester Research Explorer

\section{Citation for published version (APA):}

Hayashi, T., Hilvert, D., \& Green, A. (2018). Engineered Metalloenzymes with Non-Canonical Coordination Environments. Chemistry: A European Journal , 24(46). https://doi.org/10.1002/chem.201800975

\section{Published in:}

Chemistry: A European Journal

\section{Citing this paper}

Please note that where the full-text provided on Manchester Research Explorer is the Author Accepted Manuscript or Proof version this may differ from the final Published version. If citing, it is advised that you check and use the publisher's definitive version.

\section{General rights}

Copyright and moral rights for the publications made accessible in the Research Explorer are retained by the authors and/or other copyright owners and it is a condition of accessing publications that users recognise and abide by the legal requirements associated with these rights.

\section{Takedown policy}

If you believe that this document breaches copyright please refer to the University of Manchester's Takedown Procedures [http://man.ac.uk/04Y6Bo] or contact uml.scholarlycommunications@manchester.ac.uk providing relevant details, so we can investigate your claim.

\section{OPEN ACCESS}




\title{
Engineered Metalloenzymes with Non-Canonical Coordination Environments
}

\author{
Takahiro Hayashi, ${ }^{a}$ Donald Hilvert ${ }^{\mathrm{a} *}$ and Anthony P. Green ${ }^{\mathrm{b} *}$
}

\author{
${ }^{[\mathrm{a}]}$ Laboratory of Organic Chemistry, ETH Zurich, 8093 Zurich, Switzerland \\ ${ }^{[b]}$ School of Chemistry \& Manchester Institute of Biotechnology, The University of Manchester, 131 \\ Princess Street, Manchester M1 7DN, UK
}

\begin{abstract}
Nature employs a limited number of genetically encoded, metal coordinating residues to create metalloenzymes with diverse structures and functions. Engineered components of the cellular translation machinery can now be exploited to genetically encode non-canonical ligands with user-defined electronic and structural properties. This ability to efficiently install 'chemically programmed' ligands into proteins can provide powerful chemical probes of metalloenzyme mechanisms and presents excellent opportunities to create metalloprotein catalysts with augmented properties and novel activities. In this concept article, we provide an overview of several seminal studies describing the creation of 'chemically programmed' metalloenzymes with interesting catalytic properties, and reveal how characterization of these systems has advanced our understanding of Nature's bioinorganic mechanisms. We also highlight how powerful laboratory evolution protocols can be readily adapted to allow optimization of metalloenzymes with non-canonical ligands. This approach combines beneficial features of small molecule and protein catalysis by allowing the installation of a greater variety of local metal coordination environments into 'evolvable' protein scaffolds, and holds great promise for the future creation of powerful metalloprotein catalysts for a host of synthetically valuable transformations.
\end{abstract}

\section{Introduction}

Metalloenzymes promote a broad range of demanding transformations with high catalytic efficiencies and exacting selectivities. ${ }^{[1]}$ The enviable catalytic properties of these systems are determined by a combination of factors, including: 1) the nature of the metal cofactor (e.g. Fe, $\mathrm{Cu}, \mathrm{Zn}$, etc.), 2) the ligand set coordinating the metal cofactor, which controls the electronic properties and steric environment at the catalytic center, and 3) the protein scaffold, which is required for accurate ligand placement and further fine-tuning of the metal cofactor (Figure 1). The protein template also contains the molecular recognition elements required to orient substrates precisely for selective transformations ${ }^{[2]}$ Furthermore, systematic modification of the protein sequence via laboratory evolution allows the catalytic properties of metalloenzymes (e.g. activity, selectivity, substrate scope, stability) to be altered and optimized for desired applications in a manner not possible with small-molecule transition metal catalysts. ${ }^{[3]}$ In contrast, the greater variety of metal cofactors and ligand environments available to synthetic metal complexes gives rise to greater versatility, which enables diverse 'non-biological' transformations that are currently not achievable with enzymes. 


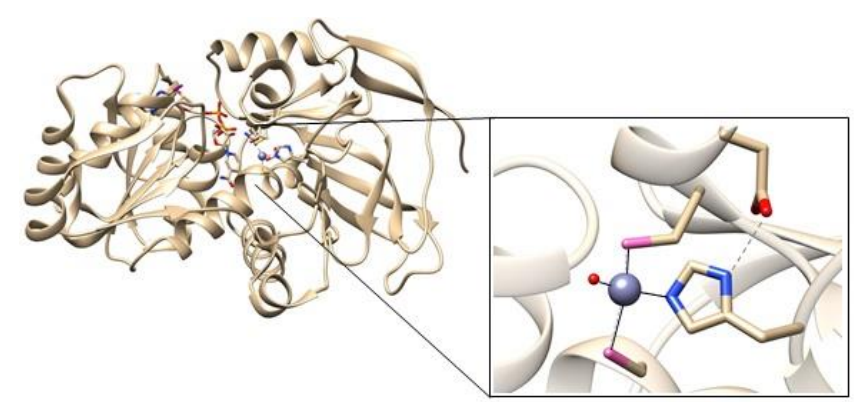

Figure 1. Structure of yeast alcohol dehydrogenase (PDB ID: 4W6Z), a metalloenzyme containing a zinc cofactor (gray) that is held in place by the side chains of three active site residues.

The complementary properties of small molecule and protein catalysts have fuelled efforts to create hybrid catalysts that combine the beneficial features of both systems. For example, active catalysts for a range of transformations have been produced by anchoring preassembled transition metal complexes into selected protein scaffolds (Figure 2a). ${ }^{[4]}$ Due to challenges associated with accurate placement of metal cofactors in substrate binding pockets, the catalytic efficiencies achieved by these hybrid systems are often lower than those achieved by the starting small molecule complex, although they can be optimized in favorable cases. For example, the activity of an artificial metalloenzyme for olefin metathesis was recently improved through genetic modification of the streptavidin host using the periplasm of $E$. coli as a reaction compartment. ${ }^{[5]}$ In general, though, optimization of these hybrid catalysts via laboratory evolution has proven to be a challenging and time-consuming process.

An attractive alternative strategy involves re-purposing the active sites of existing metalloproteins. This approach exploits existing binding pockets for substrate recognition and allows for productive interactions between metal cofactors and active site ligand environments. For instance, heme iron proteins (e.g. cytochrome P450s, cytochrome $c$ and myoglobin) have been re-engineered to promote a series of 'non-biological' carbene and nitrene transfer processes (Figure 2b). ${ }^{[6]}$ The functional capabilities of both heme and non-heme metalloproteins have been further increased by replacement of native cofactors with abiological noble metals and/or artificial metalloporphyrin analogues (Figure 2c, d). ${ }^{[7]}$ In contrast, only a handful of reports have described the creation of metalloenzymes with augmented properties or novel activities by installing 'chemically programmed' metal coordination environments into proteins using non-canonical amino acid side chains as ligands. 
a.

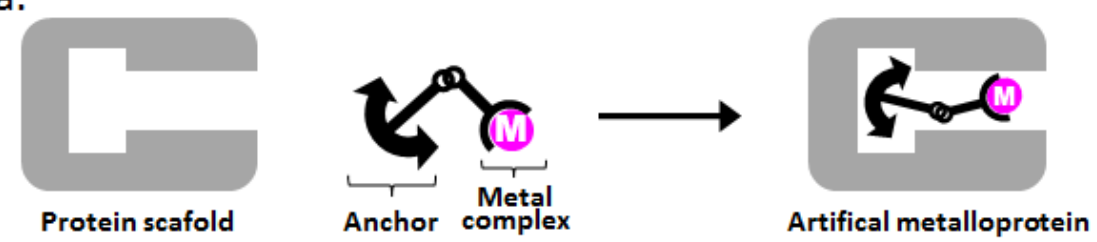

b.

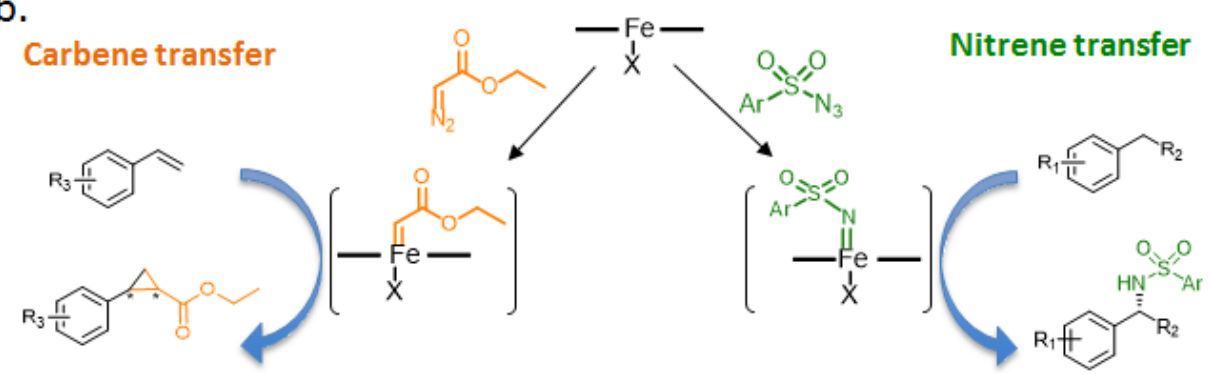

C.

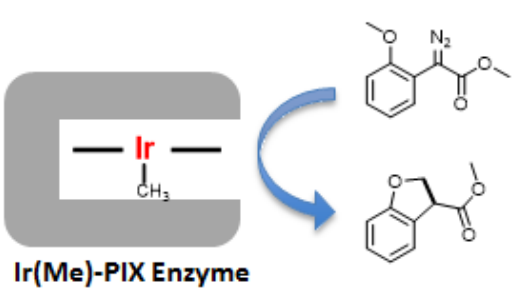

d.

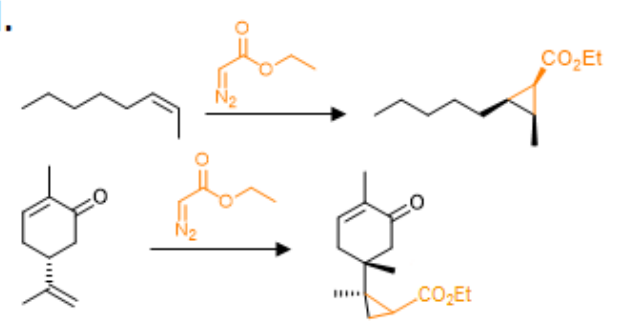

Figure 2. Strategies for metalloenzyme engineering. (a) Anchoring pre-assembled transition metal complexes into selected protein scaffolds, (b) Re-engineering heme-iron metalloenzymes to promote 'non-biological' carbene and nitrene transfer processes, and (c, d) 'direct' replacement of natural metal cofactors with non-biological noble metals to promote non-biological reactions.

The range of ligand environments accessible within proteins is typically limited to those presented by the genetic code or through Nature's biosynthetic prosthetic groups (e.g. heme). Efforts to install a greater range of ligands into metalloproteins have often resorted to the creation of 'cavity mutants,' involving replacement of large ligands by amino acids with smaller side chains (Gly or Ala) and subsequent diffusion of exogenous ligands into the vacant coordination site.$^{[8]}$ Unfortunately, the resulting ternary complexes often fail to deliver catalysts with appreciable activity, demonstrating the importance of covalent attachment of ligands to the protein backbone. An alternative approach involves the incorporation of synthetic peptide sequences into proteins through chemical ligation techniques. ${ }^{[9]}$ This approach has been used to probe the functional significance of the backbone amidate ligand in the nickel superoxide dismutase (NiSOD) active site, ${ }^{[10 a]}$ and to install a series of methionine analogues into the electron transfer protein azurin, with dramatic changes in copper redox potential observed across the series. ${ }^{[10 b]}$ However, these methods are not easily transferable to other metalloprotein templates, and the resulting chemically modified proteins cannot be readily optimized through directed evolution.

Given the importance of local ligand environments in controlling the catalytic properties of metal centers, the development of methods to expand upon the range of ligands accessible within proteins would provide a key step in merging the fields of small molecule and enzyme catalysis. By exploiting engineered components of the cellular translation machinery, it is now possible to incorporate structurally diverse amino acids into proteins in a site selective manner, typically in response to the UAG stop codon. ${ }^{[11]}$ This technology offers new 
opportunities for the installation of chemically programmed metal coordination environments into proteins, in a manner that is compatible with established laboratory evolution technologies. In this concept article, we provide an overview of several seminal studies that highlight how the incorporation of non-canonical metal coordinating amino acids into proteins can lead to the creation of metalloenzymes with augmented properties and novel activities.

\section{Heme Enzymes with Chemically Programmed Proximal Ligands}

Heme enzymes catalyze a broad range of valuable transformations with remarkable efficiency. ${ }^{[12]}$ Pentacoordinate heme iron systems contain a single genetically encoded proximal ligand, with the remaining four ligands provided by a prosthetic porphyrin cofactor. Both the identity of the proximal ligand and secondary interactions of this residue with neighboring amino acids in the proximal pocket are known to play key roles in controlling the catalytic properties of individual heme enzymes.. For example, cytochrome P450s and chloroperoxidases are characterized by proximal thiolate ligands, which differ in their hydrogen bonding interactions with nearby residues, ${ }^{[13]}$ whereas heme peroxidases utilize a histidine residue as the axial ligand, with a strong hydrogen bond formed between the noncoordinating $N_{\delta}$ atom and an aspartate residue that is conserved across the peroxidase family. ${ }^{[14]}$

The ability of cytochrome $\mathrm{P} 450$ s to functionalize unactivated $\mathrm{C}-\mathrm{H}$ bonds is dependent upon the axial cysteine thiolate ligand. ${ }^{[15]}$ Efforts to introduce less electron- donating ligands such as methionine, serine and histidine eliminate this activity, although these substitutions can open other channels of reactivity (e.g. carbene and nitrene transfers). ${ }^{[16]}$ Selenocysteine $(\mathrm{Sec})$ represents a more conservative substitution suited to probing relationships between electron donation from the proximal ligand and $\mathrm{P} 450$ reactivity. Sec is a rare proteinogenic amino acid that is incorporated into proteins by stop codon suppression in a natural expansion of the genetic code. ${ }^{[17]}$ This machinery has been harnessed to replace the axial cysteine ligand of P450cam with Sec. ${ }^{[18]}$ Analogous Sec-containing versions of CYP119 and CYP125 have been prepared in cysteine auxotrophic strains of $E$. coli supplemented with Sec. ${ }^{[19]}$

Comparison of the P450cam and SeP450cam crystal structures confirms that the Cys $\rightarrow$ Sec constitutes a highly conservative mutation, with the geometry and environment of the heme ligand fully preserved in the modified enzyme (Figure 3a). ${ }^{[18]}$ However, introduction of the more electron-donating selenolate ligand causes distinct changes to the electronic properties of the heme iron, including a lowered FeIII/FeII redox potential, redshifts of the absorption maxima in the UV/Vis spectra, and perturbation of the resting state spin equilibrium in favor of the low spin species. This spin state perturbation raises the intriguing possibility of exploiting the heavy selenium atom to explore the importance of spin equilibria and spin crossovers in P450 chemistry. SeP450cam* maintains the high monooxygenase activity displayed by the parent enzyme, with only a modest 2 -fold reduction in the rate of camphor hydroxylation observed (Figure 3b-i). Introduction of the selenolate ligand also has relatively modest effects on substrate, product and oxygen binding, electron transfer and coupling efficiency. ${ }^{[20]}$ The only step significantly altered by Sec incorporation is off-pathway reduction of oxygen to superoxide which is accelerated by 250 -fold in SeP450cam (vs $\mathrm{P} 450 \mathrm{cam}$ ) (Figure 3b-ii). However, this increased rate of $\mathrm{O}_{2}$ reduction has negligible impact on overall catalytic turnover since the on-cycle second electron transfer step remains considerably faster than this off-pathway process.

Cyp125 promotes the sequential oxidation of the terminal C26 methyl group of cholesterol to the alcohol, aldehyde and finally the carboxylic acid. ${ }^{[21]}$ The mechanism of carboxylic acid 
formation is believed to involve classical hydrogen atom abstraction and subsequent oxygen transfer by compound I. In addition to the conventional acid metabolite, the wild-type enzyme also catalyzes the generation of deformylation by-products, formed following addition of a ferric-peroxo anion to the aldehyde intermediate. Proximal ligand Cys $\rightarrow$ Sec substitution in Cyp125 resulted in an increased production of carboxylic acid at the expense of the deformylation products. ${ }^{[19 \mathrm{~b}]}$ This altered product profile is consistent with an increased $\mathrm{p} K_{\mathrm{a}}$ of the ferric-peroxo anion in the selenoenzyme due to increased electron donation from the axial ligand, which favors its protonation and subsequent compound I formation over nucleophilic addition onto an electrophilic aldehyde intermediate (Figure 3c).

More recently, the preparation of compound I in wild-type and Sec-ligated Cyp119 was achieved following treatment of the resting enzyme with $m$-CPBA under carefully optimized conditions. ${ }^{[2]}$ Characterization of these species by EPR and Mössbauer spectroscopies revealed increased asymmetry around the ferryl moiety in the selenoenzyme, consistent with increased electron donation from the proximal selenolate ligand. The application of 'target testing' to reactions of m-CPBA with premixed enzyme (CYP119 or SeCYP119)/substrate (hexanoic acid or perdeuterated hexanoic acid) solutions revealed that that seleno-ligated compound $\mathrm{I}$ is more reactive towards $\mathrm{C}-\mathrm{H}$ bonds than the wild-type counterpart, thus providing a direct link between electron donation from the proximal ligand and compound I reactivity (Figure 3d).
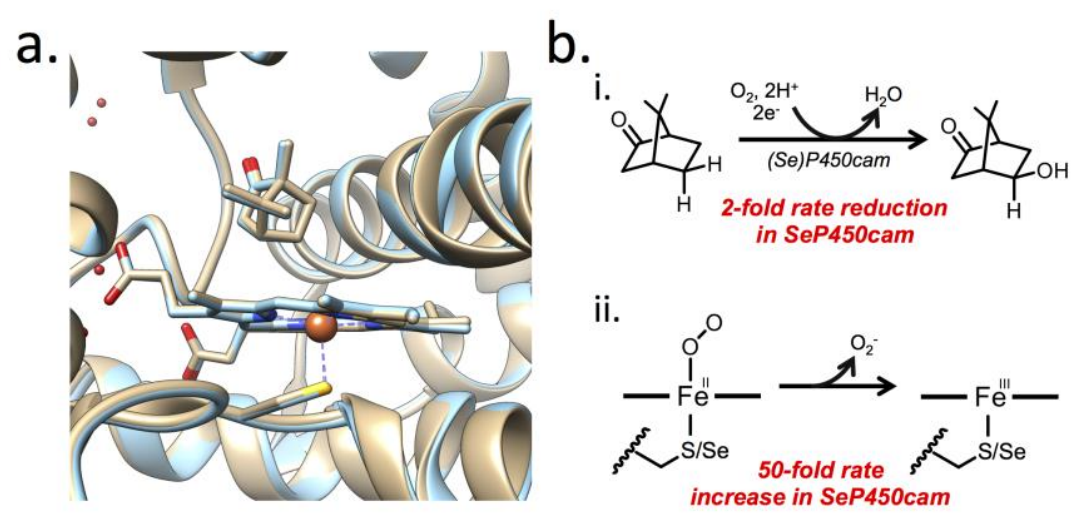

C.
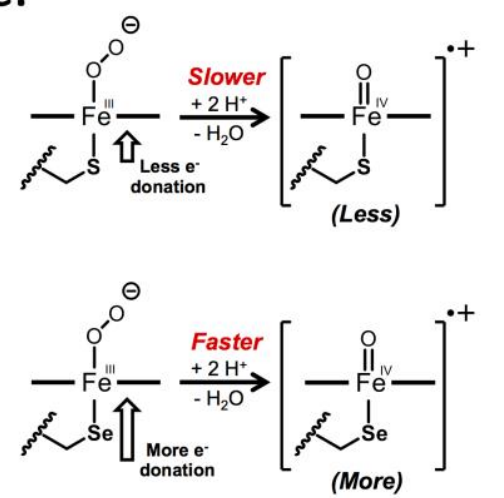

d.
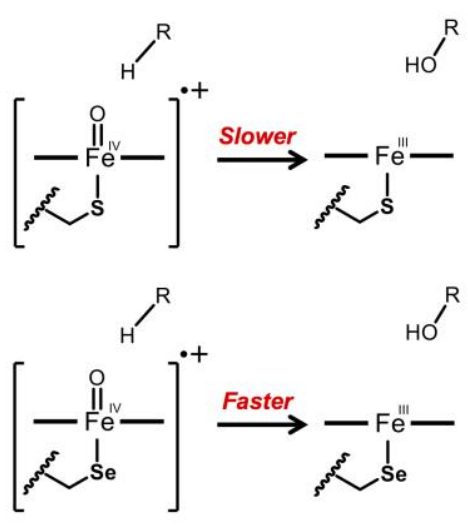

Figure 3. Active site structure and catalytic properties of P450 and SeP450. (a) Overlay of P450cam and SeP450cam active sites (PDB ID: 3FWG and 3FWF, respectively). (b) Catalytic properties of $\mathrm{P} 450$ vs SeP450. (c) Increased electron donation in SeP450 favors protonation of the ferric-peroxo anion and subsequent compound I formation. (d) Selenoligated compound I exhibits increased reactivity towards $\mathrm{C}-\mathrm{H}$ bonds than the wild-type counterpart. 
The studies on modified P450s highlight how the installation of novel proximal ligands can impact upon our understanding of heme enzyme mechanisms. We have recently extended this approach to probe the importance of proximal pocket coordination environment in histidine ligated systems. ${ }^{[23]}$ Heme peroxidases utilize hydrogen peroxide as an electron acceptor to promote a range of oxidative transformations (Figure 4b). ${ }^{[12 a]}$ The Asp-His-Fe peroxidase triad is among the most widely studied catalytic motifs in biochemistry (Figure 4a). ${ }^{[14]}$ In particular, significant efforts have been devoted to elucidating the role of a conserved hydrogen bond formed between the proximal His ligand and a neighboring active site aspartate (Figure 4a). It is well established that substitution of either the Asp or His residues with an alternative canonical amino acid leads to a dramatic reduction in enzyme activity. ${ }^{[14 \mathrm{c}]}$ Thus, standard mutagenesis methods do not allow disruption of the Asp-His hydrogen bond while maintaining functional peroxidase activity, which severely restricts the degree of mechanistic information that can be uncovered using this approach. Expansion of the genetic code to include histidine analogues allowed us to explore the significance of the peroxidase Asp-His hydrogen bond from an alternative angle, involving direct substitution of the proximal histidine ligand with a structurally related analogue $N_{\delta}$-methyl histidine $(\mathrm{NMH}){ }^{[29]}$

a.

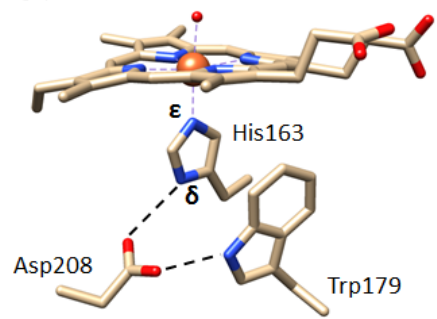

b.

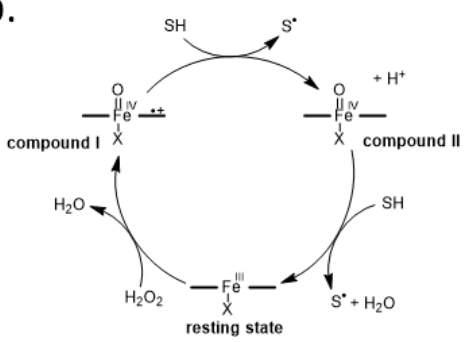

Figure 4. Active site structure and catalytic cycle of heme peroxidase. (a) The active site of ascorbate peroxidase (PDB ID: 1OAG), illustrating the conserved His-Asp hydrogen bond (b) The catalytic cycle of heme peroxidases. Adapted with permission from reference 23a. Copyright 2016 American Chemical Society.

An engineered pyrrolysyl-tRNA synthetase/pyrrolysl-tRNA (PylRS NMH $_{\text {tRNA }}{ }^{\mathrm{Pyl}}$ ) pair, which selectively encodes NMH in response to the UAG stop codon, ${ }^{[24]}$ was used to install a proximal NMH ligand into an engineered ascorbate peroxidase (APX2) in place of the native histidine. ${ }^{[23 \mathrm{a}]}$ The $\mathrm{x}$-ray crystal structure of APX2 NMH confirmed that introduction of the $\mathrm{NMH}$ proximal ligand results in only minor structural perturbations, with no significant changes in the location of the iron cofactor or the heme plane, and minimal conformational adjustment of key proximal pocket residues (Figure 5a). 

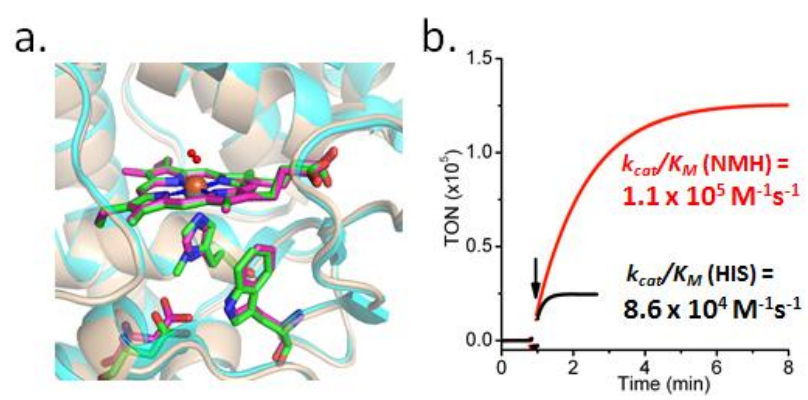

Figure 5. Structural and kinetic characterization of APX2 with NMH. (a) Overlay of APX and APX2 NMH active sites (PDB ID: 1OAG and 5L86, respectively). (b) Representative time course of guaiacol oxidation by APX2 and APX2 NMH. Adapted with permission from reference 23a. Copyright 2016 American Chemical Society.

Remarkably, despite disruption of the proximal pocket Asp-His hydrogen bond, introduction of a proximal NMH ligand into APX2 results in a minor increase in the catalytic efficiency of guaiacol oxidation. ${ }^{[23 a]}$ Furthermore, APX2 NMH is able to perform a significantly higher number of turnovers than APX2 prior to irreversible deactivation, with total turnover numbers (TONs) of 31,300 and 6,200 determined for APX2 NMH and APX2, respectively (Figure 5b). Higher TONs were also observed for oxidation of a range of electron rich aromatic substrates, including phenol, $O$-anicidine and $o$-cresol. In addition to these substantial improvements in catalytic parameters, it was demonstrated that introduction of the proximal NMH ligand imparts a degree of mutational flexibility at the proximal pocket aspartate residue (Asp208). APX2 is almost completely intolerant to substitutions at this key active site residue. In contrast, D208A, D208N and D208M variants of APX2 NMH retained appreciable levels of peroxidase activity. These observations illustrate how the introduction of non-canonical ligands can enhance catalytic performance while simultaneously simplifying catalytic mechanism. This capability is likely to facilitate future efforts to design and/or evolve new active site heme environments within proteins.

Myoglobin is an oxygen-binding protein that possesses only low levels of promiscuous peroxidase activity. ${ }^{[25]}$ The strong proximal pocket Asp-His hydrogen bonding interaction that is characteristic of natural peroxidases is absent in myoglobin, which is believed to be a contributing factor to the weak peroxidase activity displayed by this protein. ${ }^{[26]}$ Nevertheless, efforts to install a functional Asp-His-Fe triad into related globins have failed to deliver enhancements in catalytic parameters. ${ }^{[27]}$ In light of the improved catalytic performance of APX2 NMH vs APX2, we elected to replace the proximal histidine ligand of sperm whale myoglobin $(\mathrm{Mb})$ with a genetically encoded NMH residue (Figure 6a). ${ }^{[23 \mathrm{~b}]}$ Comparison of the crystal structures of $\mathrm{Mb}$ and $\mathrm{Mb} \mathrm{NMH}(1.48 \AA)$ reveals significant structural changes occurring within the proximal pocket resulting from proximal ligand substitution, including a $100^{\circ}$ rotation of the imidazole plane of the proximal ligand and alterations to hydrogen bonding interactions between the proximal ligand, Ser92 and the prosthetic porphyrin cofactor (Figure 6a). 

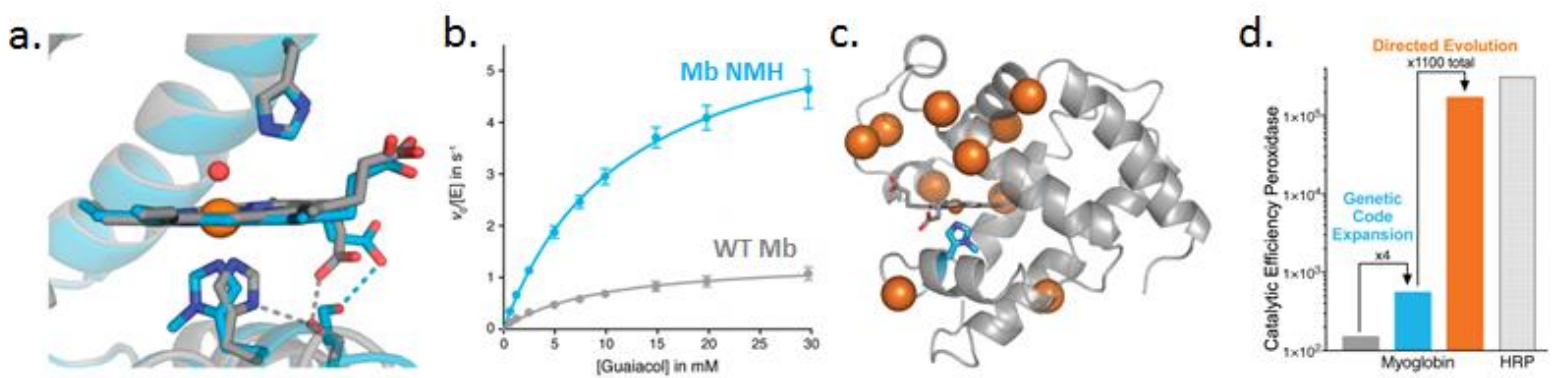

Figure 6. Structural and kinetic characterization of $\mathrm{Mb} \mathrm{NMH}$ and its evolved descendants. (a) Overlay of the $\mathrm{Mb}$ and $\mathrm{Mb} \mathrm{NMH}$ active sites (PDB ID: 1A6K and 5OJ9, respectively), and (b) Michaelis-Menten plots of guaiacol oxidation by $\mathrm{Mb}$ and $\mathrm{Mb} \mathrm{NMH}$. Also shown are (c) a 'mutational map' of the most evolved Mb NMH and (d) the relative efficiencies of individual variants compared to wt $\mathrm{Mb}$ and horseradish peroxidase. Adapted with permission from reference 23b. Copyright 2018 American Chemical Society.

Introduction of a proximal NMH ligand into $\mathrm{Mb}$ results in a substantial 3.7-fold increase in the catalytic efficiency of guaiacol oxidation, which is dominated by an increase in $k_{\text {cat }}(1.4 \mathrm{vs}$ $6.6 \mathrm{~s}^{-1}$ ) (Figure 6b). This increased efficiency can be rationalized by the increase in redox potential (FeII/FeIII) observed for Mb NMH $(138 \mathrm{mV})$ compared to $\mathrm{Mb}(65 \mathrm{mV})$. The observed second-order rate constant for the formation of ferryl-oxo catalytic intermediates was also significantly increased in $\mathrm{Mb} \mathrm{NMH}\left(k_{\mathrm{obs}}=2800 \mathrm{M}^{-1} \mathrm{~s}^{-1}\right)$ compared with $\mathrm{Mb}\left(k_{\mathrm{obs}}=\right.$ $\left.800 \mathrm{M}^{-1} \mathrm{~s}^{-1}\right)$.

Despite the improved catalytic performance compared with wild-type $\mathrm{Mb}, \mathrm{Mb} \mathrm{NMH}$ remains a modestly active catalyst compared with natural peroxidases. Introduction of four mutations close to the active site, which had previously been shown to enhance the peroxidase activity of wild-type $\mathrm{Mb}$, afforded an MbQ NMH variant with a further $~ 140$-fold increased catalytic efficiency. ${ }^{[25]}$ The activity of MbQ NMH was further improved over several rounds of directed evolution using an established assay based on Amplex Red oxidation, affording a variant (MbQ2.1 NMH) with a $k_{\text {cat }} / K_{\mathrm{M}}$ value of $1.5 \times 10^{6} \mathrm{M}^{-1} \mathrm{~s}^{-1}$ (Amplex oxidation), which is ten-fold higher than MbQ NMH and 50 fold higher than wildtype ascorbate peroxidase (APX). A second variant (MbQ2.2 NMH) proved be a superior catalyst for guaiacol oxidation, with a catalytic efficiency $\sim 1,140$ fold and $\sim 13$ fold higher than wild-type $\mathrm{Mb}$ and wild-type APX, respectively, and only $\sim 2$ fold lower than HRP. (Figure 6c and d). A total of seven mutations accumulated in each variant during evolution compared with the starting MbQ NMH template, with five substitutions common to both MbQ2.1 NMH and MbQ2.2 NMH. In addition to improved catalytic efficiencies, the TONs steadily increased from wild-type $\mathrm{Mb}$ to the most highly engineered variants. Thus fine tuning of the local metal coordination environment of myoglobin through the installation of a chemically programmed NMH ligand, combined with further optimization of the protein scaffold via laboratory evolution, led to the development of efficient peroxidase biocatalysts in a globin fold with catalytic efficiencies approaching those of natural peroxidases. ${ }^{[23 b]}$

\section{Genetically encoded ligands which mimic post-translational modifications}

Heme copper oxidases (HCOs) catalyze the selective four-electron reduction of molecular oxygen to water without releasing reactive oxygen species (ROS, e.g. peroxide and superoxide). ${ }^{[28]}$ The active site of HCO consists of a heterobinuclear metal center containing a heme iron and a copper center $\left(\mathrm{Cu}_{\mathrm{B}}\right)$ coordinated by three histidine residues (Figure 7b). ${ }^{[29]}$ The $\mathrm{N}_{\varepsilon}$ of one of these His ligands forms a crosslink with the C6 atom of a neighboring 
tyrosine residue in a posttranslational modification (PTM) that is conserved across bacterial and mammalian HCOs. ${ }^{[30]}$

To gain insights into the functional significance of the Tyr-His cross-link, Liu et al. evolved an orthogonal Methanococcus jannaschii tyrosyl-tRNAsynthetase/tyrosyl-tRNA $\left(M j\right.$ TyrRS/MjtRNA $\left.{ }^{\text {Tyr }}\right)$ pair to selectively encode $(S)$-2-amino-3-(4-hydroxy-3-(1H-imidazol1-yl)phenyl)propanoic acid (ImiTyr, Figure 7a) in response to the UAG codon. ${ }^{[31]}$ Based on previous work on functional HCO models in $\mathrm{Mb},{ }^{[32]}$ ImiTyr 1 was incorporated into $\mathrm{Mb}$ at position 33 (Figure 7b). An additional Leu29His substitution, together with the native His64 residue makes up the copper binding site which mimics that of $\mathrm{CuB}$ in HCOs. The resulting $\mathrm{HCO}$ model ( $\mathrm{ImiTyrCu} \mathrm{B}_{\mathrm{B}} \mathrm{Mb}$ ) performed $>1000$ cycles of oxygen reduction to water, while producing less than 6\% ROS (Figure 7c). Interestingly, removal of the copper ion from ImiTyrCu $\mathrm{B}_{\mathrm{B}} \mathrm{Mb}$ did not dramatically alter the overall rate of oxygen reduction, but did lead to diminished selectivity, with $30 \%$ of oxygen converted to ROS (Figure 7c). Most significantly, ImiTyrCu $\mathrm{B}_{\mathrm{B}} \mathrm{Mb}$ was found to be eightfold more selective (reduction to water vs. reduction to ROS), and able to perform 3 times as many turnovers as an analogous $\mathrm{HCO}$ model F33YCuBMb lacking the His-Tyr crosslink but harboring individual histidine and tyrosine residues at similar positions in the same protein. Thus the installation of a genetically encoded ImiTyr ligand into myoglobin reveals significant insights into the functional role of the His-Tyr cross link in HCOs, and may facilitate the creation of practical biocatalysts for $\mathrm{O}_{2}$ reduction in simple and robust protein scaffolds like myoglobin.

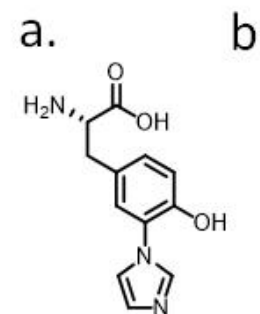

b.

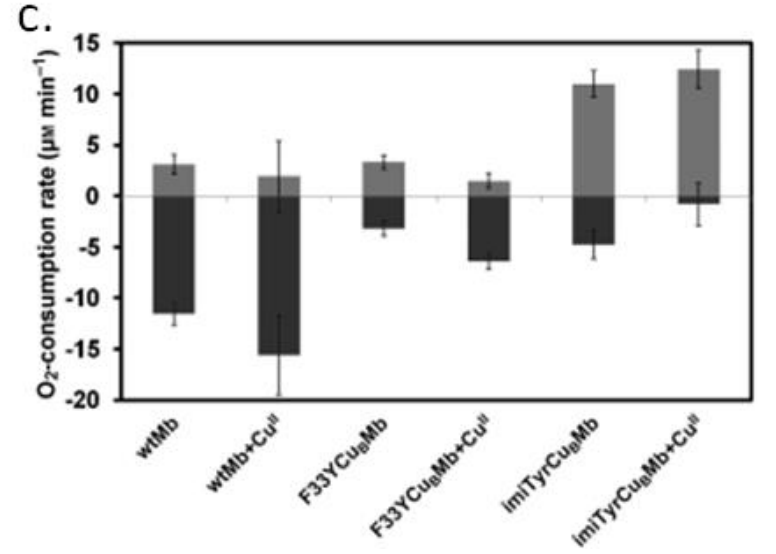

Figure 7. Structural model and oxygen reduction activity of the heme copper oxidase mimic ImiTyrCu $\mathrm{B}_{\mathrm{B}} \mathrm{Mb}$. (a) Structure of ImiTyr. (b) Heme $a_{3}-\mathrm{Cu}_{\mathrm{B}}$ site of cytochrome $c$ oxidase (left) and structure model of $\mathrm{ImiTyrCu}_{\mathrm{B}} \mathrm{Mb}$ (cyan) and $\mathrm{F} 33 \mathrm{YCu}_{\mathrm{B}} \mathrm{Mb}$ (yellow) (right). (c) Rate of oxygen reduction to form either water (light gray) or ROS peroxide and superoxide (dark gray). Adapted with permission from reference 31. Copyright 2012 Wiley-VCH Verlag $\mathrm{GmbH} \& \mathrm{Co}$. KGaA. 


\section{Artificial metalloenzymes containing metal chelating amino acids}

Engineered aminoacyl-tRNA synthetases have been developed to incorporate several metalchelating amino acids into proteins, including (2,2'-bipyridin-5-yl)alanine (Bpy-Ala) and (8hydroxyquinolin-3-yl)alanine. ${ }^{[33]}$ The high metal binding affinity of these chelating ligands should facilitate the creation of well-defined metal coordination sites within proteins.

Lee et al. engineered a metal binding site into the E. coli catabolite activator protein (CAP) by replacing Lys26 with Bpy-Ala. ${ }^{[34]} \mathrm{CAP}$ binds as a homodimer to a 22 base pair DNA consensus sequence, inducing an approximately $90^{\circ}$ bend in the double helix. The crystal structure of a CAP-DNA complex shows that Lys26 lies at the protein-DNA interface in proximity to base pairs 1 and 22 of the DNA recognition sequence. The Lys $26 \rightarrow$ Bpy-Ala substitution in CAP led to the creation of a protein capable of promoting site-specific DNA cleavage. In the presence of redox active metals like $\mathrm{Fe}(\mathrm{II})$ or $\mathrm{Cu}(\mathrm{II}), 3$-mercaptopropionic acid or ascorbate as a reductant, and the allosteric effector cAMP, CapK26Bpy-ala promoted the oxidative cleavage of a 50 base pair DNA fragment at two different sites, between nucleotides 14 and 15 on the 5'-side of the binding site and nucleotides 37 and 38 on the 3'side, suggesting that a diffusible oxidizing agent is responsible for DNA cleavage. Under the same conditions, no cleavage was observed with wild-type CAP or in the absence of a reducing agent. Since Bpy-Ala can be readily installed into proteins at different sites, this approach can be applied in principle to map protein-DNA interactions in the absence of structural information.

The incorporation of Bpy-Ala (Figure 8a) into selected sites of an engineered variant of the transcription factor Lactoccocal multidrug resistance regulator (LmrR_LM) (Figure 8b, left) led to the generation of artificial copper $(\mathrm{Cu}(\mathrm{II}))$ metalloproteins that serve as chiral Lewis acids capable of promoting enantioselective vinylogous Friedel-Crafts alkylations. ${ }^{[35]}$ The LmrR_LM M89BpyAla variant catalyzed the reaction of the reaction of 5-methoxy- $1 \mathrm{H}$ indole and 1-(1-methyl-1H-imidazol-2-yl) but-2-en-1-one with modest selectivity (e.e. 49\%), albeit with reduced conversion (27\%) compared to the analogous reaction catalyzed by free $\mathrm{Cu}\left(\mathrm{NO}_{3}\right)_{2}$ in solution (98\%) (Figure 8c). Selectivity was further improved (e.e. 66\%) through targeted mutagenesis, and catalysts with the opposite stereochemical preference were obtained by altering the site of BpyAla incorporation. Substrate profiling of selected variants based on the LmrR_LM M89BpyAla template with a small panel of indole derivatives revealed a LmrR_LM M89BpyAla F93W variant which catalyzed the alkylation of 2-methyl indole in $83 \%$ e.e. ( $94 \%$ conversion). In addition to LmrR, several multidrug resistance regulators from the TetR family have been explored as scaffolds for the creation of artificial copper metalloenzymes (Figure 8b, right). ${ }^{[36]}$ A Y123BpyAla variant of QacR proved to be a particularly promising catalyst for vinylogous Friedel-Crafts alkylations, catalyzing the reaction of 2-methyl indole and 1-(1-methyl-1H-imidazol-2-yl) but-2-en-1-one with an e.e. of $94 \%$ e.e. in favor of the opposite enantiomer to that formed with the LmrR_LM M89BpyAla variants (Figure 8c). 


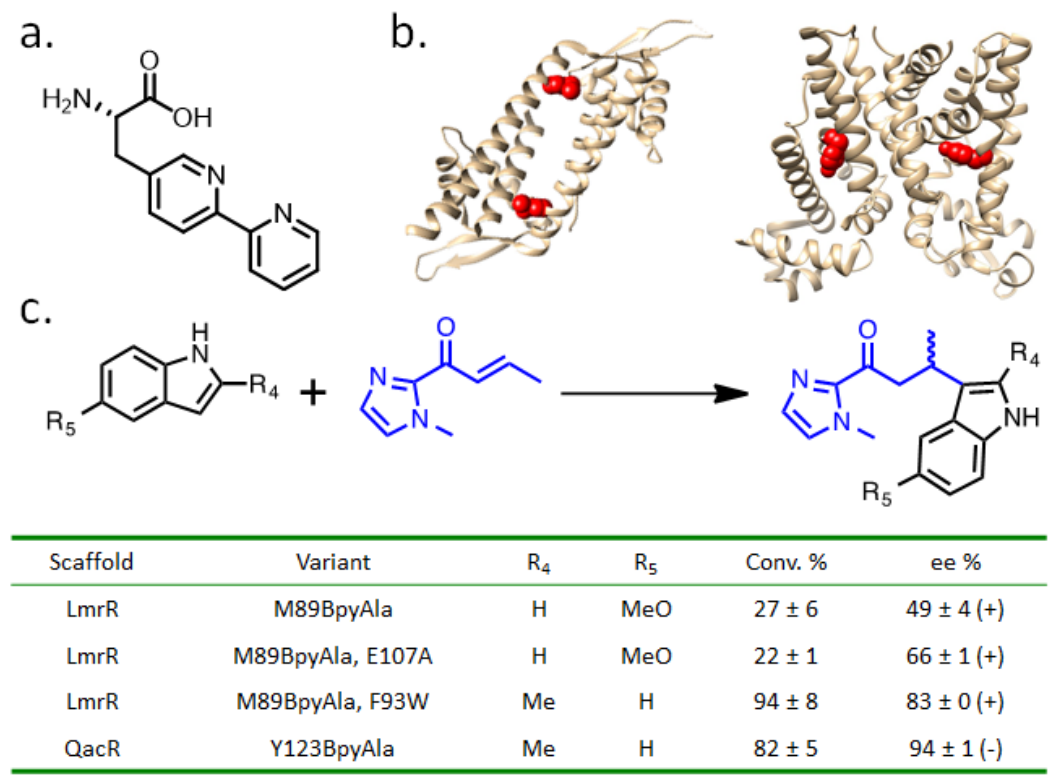

d.<smiles>[R]C=CC(=O)c1ccccn1</smiles>

e.

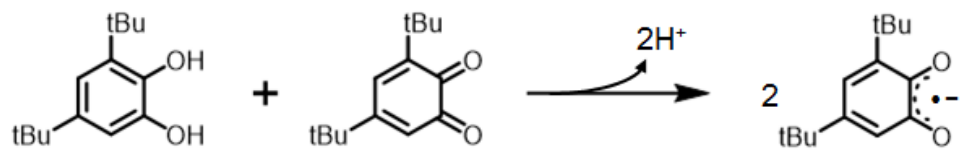

Figure 8. Structures and functions of artificial metalloenzymes containing non-canonical BpyAla ligands in the LmrR and QacR scaffolds. (a) Structure of BpyAla. (b) Structure of dimeric LmrR (left, PDB ID: 3F8F) and QacR (right, PDB ID: 1JTY) with M89 and Y123 shown as red spheres. (c) Summary of vinylogous Friedel-Crafts alkylations catalyzed by LmrR and QacR variants. (d) Enantioselective hydrations of enones. (e) LmrR variants bind and stabilize semiquinone radicals formed by comproportionation between di-tertbutylcatechol and di-tert-butylquinone.

The synthetic utility of LmrR_LM M89BpyAla variants was recently extended to include enantioselective hydrations of enones (Figure 8d) ${ }^{[37]}$ Natural hydratases exploit a judiciously positioned general base to activate the nucleophilic water molecule. Inspired by these natural catalytic mechanisms, computational methods were used to predict suitable sites in the LmrR_LM M89BpyAla to install a carboxylate group to serve as a general base. A V15E variant gave superior reaction conversions and selectivities compared with the starting template. Although the catalytic efficiencies of the artificial metalloenzymes created in the LmrR template remain modest, these studies demonstrate that the installation of metal chelating amino acids into proteins can lead to the creation of metalloprotein catalysts for non-biological, enantioselective transformations. In an interesting recent development, the Roelfes group described the binding and stabilization of semiquinone radicals (Figure 8e) by artificial metalloproteins containing a number of first row metals in the LmrR_LM M89BpyAla template. ${ }^{[38]}$ Although catalytic function has not been demonstrated, this study 
may provide a first step towards harnessing the chemistry of unstable radicals, with potential future applications in catalysis.

\section{Outlook and Conclusions}

The selected studies described within this concept article demonstrate that the incorporation of non-canonical metal coordination environments into proteins can lead to the creation of metalloenzymes with augmented properties and novel activities. Incorporation of chemically programmed ligands directly through the translation machinery presents opportunities for further optimization of enzyme function (e.g. activity, selectivity, substrate scope) via laboratory evolution. These early examples also serve to highlight areas for future investigation. A recent report describing the functional replacement of a key histidine ligand in the zinc metalloenzyme mannose-6-phosphate isomerase by $\mathrm{NMH}$, leading to the generation of an organism whose growth was strictly dependent on the non-canonical amino acid, highlights a simple and potentially versatile strategy for the biocontainment of recombinant organisms. ${ }^{[39]}$ The creation of metalloenzymes that promote synthetically useful 'non-biological' reactions with the enormous rate accelerations associated with Nature's enzymes is an ambitious goal that has yet to be realized. The availability of chemically programmed, metal coordination environments has the potential to dramatically impact upon the efficiencies of these non-biological processes. Likewise, the integration of non-canonical ligands into computational design algorithms is likely to facilitate the 'bottom up' creation of efficient metalloenzymes with novel activities. ${ }^{[4 e, 40,41]}$ Finally, the availability of chemically programmed ligands within proteins may provide superior coordination environments to support catalysis with noble metal cofactors (e.g. Ir, Rh, Pd, Ru), which often possess intrinsically superior catalytic properties than base metal centers. ${ }^{[7]}$ Thus continued expansion of the genetic code to include a greater range of chemically programmed ligands will provide a crucial link between the complementary disciplines of small molecule and enzyme catalysis, and holds great promise for the creation of hybrid catalysts with novel activities.

\section{Acknowledgments}

The authors gratefully acknowledge the European Research Council (ERC Starter Grant, Grant number 757991, APG), the Biotechnology and Biological Sciences Research Council (David Phillips Fellowship BB/M027023/1, APG), the Swiss National Science Foundation (31003A_156276, DH), ETH Zurich (DH) and a JSPS fellowship (TH) for generous funding.

\section{Keywords}

Non-canonical amino acid, metalloenzyme, directed evolution, heme enzymes, biocatalysis. 


\section{References}

[1] a) H. B. Gray, Proc. Natl. Acad. Sci. U.S.A. 2003, 100, 3563-3568. b) Y. Lu, N. Yeung, N. Sieracki, N. M. Marshall, Nature 2009, 460, 855-862.

[2] Lewis, J. C., P. S. Coelho, F. H. Arnold, Chem. Soc. Rev. 2011, 40, 2003-2021.

[3] a) F. H. Arnold, Nature 2001, 409, 253-257; b) C. Jackel, P. Kast, D. Hilvert, Annu. Rev. Biophys. 2008, 37, 153-173. c) U. T. Bornscheuer, G. W. Huisman, R. J. Kazlauskas, S. Lutz, J. C. Moore, K. Robins, Nature 2012, 485, 185-194.

[4] a) J. Collot, J. Gradinaru, N. Humbert, M. Skander, A. Zocchi, T. R. Ward, J. Am. Chem. Soc. 2003, 125, 9030-9031. b) C. A. Kruithof, M. A. Casado, G. Guillena, M. R. Egmond, A. van der Kerk-van Hoof, A. J. Heck, R. J. Klein Gebbink, G. van Koten, Chem. Eur. J. 2005, 11, 6869-6877. c) T. R. Ward, Acc. Chem. Res. 2011, 44, 47-57. d) T. K. Hyster, L. Knorr, T. R. Ward, T. Rovis, Science 2012, 338, 500-503. e) T. Heinisch, M. Pellizzoni, M. Durrenberger, C. E. Tinberg, V. Kohler, J. Klehr, D. Haussinger, D. Baker, T. R. Ward, J. Am. Chem. Soc. 2015, 137, 10414-10419.

[5] M. Jeschek, R. Reuter, T. Heinisch, C. Trindler, J. Klehr, S. Panke, T. R. Ward, Nature 2016, 537, 661-665.

[6] a) C. K. Prier, R. K. Zhang, A. R. Buller, S. Brinkmann-Chen, F. H. Arnold, Nat. Chem. 2017, 9, 629-634. b) P. S. Coelho, E. M. Brustad, A. Kannan, F. H. Arnold, Science 2013, 339, 307-310; c) M. Bordeaux, V. Tyagi, R. Fasan, Angew. Chem. Int. Ed. 2015, 54, 1744-1748; d) S. B. Kan, R. D. Lewis, K. Chen, F. H. Arnold, Science 2016, 354, 1048-1051.

[7] a) H. M. Key, P. Dydio, D. S. Clark, J. F. Hartwig, Nature 2016, 534, 534-537. b) P. Dydio, H. M. Key, A. Nazarenko, J. Y. Rha, V. Seyedkazemi, D. S. Clark, J. F. Hartwig, Science 2016, 354, 102-106. c) G. Sreenilayam, E. J. Moore, V. Steck, R. Fasan, Adv. Synth.Cat. 2017; 359, 2076-2089. d) Q. Jing, K. Okrasa, R. J. Kazlauskas, Chem. Eur. J. 2009, 15, 13701376. e) Jing, Q. R. J. Kazlauskas, ChemCatChem 2010, 2, 953-957. f) T. Matsuo, K. Fukumoto, T. Watanabe, T. Hayashi, Chem. Asian. J. 2011, 6, 2491-2499. g) M. Ohashi, T. Koshiyama, T. Ueno, M. Yanase, H. Fujii, Y. Watanabe, Angew. Chem. Int. Ed. 2003, 42, 1005-1058. h) T. Hayashi, H. Dejima, T. Matsuo, H. Sato, D. Murata, Y. Hisaeda, J. Am. Chem. Soc. 2002, 124, 11226-11227. K. Oohora, Y. Kihira, E. Mizohata, T. Inoue, T. Hayashi, J. Am. Chem. Soc. 2013, 135, 17282-17285.

[8] a) J. H. Dawson, A. E. Pond, M. P. Roach, Biopolymers 2002, 67, 200-206. b) J. Hirst, S. K. Wilcox, P. A. Williams, J. Blankenship, D. E. McRee, D. B. Goodin, Biochemistry 2001, 40, 1265-1273. c) J. Du, M. Sono, J. H. Dawson, Coordin Chem Rev 2011, 255, 700-716. d) H. J. Wijma, M. J. Boulanger, A. Molon, M. Fittipaldi, M. Huber, M. E. P. Murphy, Martin Ph. Verbeet, G. W. Canters, Biochemistry 2003, 42, 4075-4083.

[9] a) Y. Lu, Curr. Opin. Chem. Biol. 2005, 9, 118-126. b) T. M. Muir, Annu. Rev. Biochem. 2003, 72, 249-289. c) T. J. R. Harmand, C. E. Murar, J. W Bode, Curr. Opin. Chem. Biol. 2014, 22, 115-121.

[10] D. K. Garner, M. D. Vaughan, H. J. Hwang, M. G. Savelieff, S. M. Berry, J. F. Honek, Y. Lu, J. Am. Chem. Soc. 2006, 128, 15608-15617.

[11] a) C. C. Liu, P. G. Schultz, Annu. Rev. Biochem. 2010, 79, 413-444. b) W. Wan, J. M. Tharp, W. R. Liu, Biochim. Biophys. Acta 2014, 1844, 1059-1070. 
[12] a) T. L. Poulos, Chem. Rev. 2014, 114, 3919-3962. b) X. Huang, J. T. Groves, Chem. Rev. 2017, 118, 2491-2553.

[13] C. M. Krest, A. Silakov, J. Rittle, T. H. Yosca, E. L. Onderko, J. C. Calixto, M. T. Green, Nat. Chem. 2015, 7, 696-702.

[14] a) T. L. Poulos, J. Biol. Inorg. Chem. 1996, 1, 356-359. b) D. B. Goodin, J. Biol. Inorg. Chem. 1996, 1, 360-363. c) D. B. Goodin, D. E. McRee, Biochemistry 1993, 32, 3313-3324.

[15] T. H. Yosca, J. Rittle, C. M. Krest, E. L. Onderko, A. Silakov, J. C. Calixto, R. K. Behan, M. T. Green, Science 2013, 342, 825-829.

[16] a) P. S. Coelho, Z. J. Wang, M. E. Ener, S. A. Baril, A. Kannan, F. H. Arnold, E. M. Brustad, Nat. Chem. Biol. 2013, 9, 485-487. b) Z. J. Wang, H. Renata, N. E. Peck, C. C. Farwell, P. S. Coelho, F. H. Arnold, Angew. Chem. Int. Ed. 2014, 53, 6810-6813.

[17] T. C. Stadtman, Annu. Rev. Biochem. 1996, 65, 83-100.

[18] C. Aldag, I. A. Gromov, I. Garcia-Rubio, K. von Koenig, I. Schlichting, B. Jaun, D. Hilvert, Proc. Natl. Acad. Sci. U.S.A. 2009, 106, 5481-5486.

[19] a) Y. Y. Jiang, S. Sivaramakrishnan, T. Hayashi, S. Cohen, P. Moenne-Loccoz, S. Shaik, P. R. O. de Montellano, Angew. Chem. Int. Ed. 2009, 48, 7193-7195. b) S. Sivaramakrishnan, H. Ouellet, H. Matsumura, S. H. Guan, P. Moenne-Loccoz, A. L. Burlingame, P. R. O. de Montellano, J. Am. Chem. Soc. 2012, 134, 6673-6684.

[20] A. Vandemeulebroucke, C. Aldag, M. T. Stiebritz, M. Reiher, D. Hilvert, Biochemistry 2015, $54,6692-6703$.

[21] H. Ouellet, S. H. Guan, J. B. Johnston, E. D. Chow, P. M. Kells, A. L. Burlingame, J. S. Cox, L. M. Podust, P. R. O. de Montellano, Mol. Microbiol. 2010, 77, 730-742.

[22] E. L. Onderko, A. Silakov, T. H. Yosca, M. T. Green, Nat. Chem. 2017, 9, 623-628.

[23] a) A. P. Green, T. Hayashi, P. R. Mittl, D. Hilvert, J. Am. Chem. Soc. 2016, 138, 1134411352. b) M. Pott, T. Hayashi, T. Mori, P. R. E. Mittl, A. P. Green, D. Hilvert, J. Am. Chem. Soc. 2018, 140, 1535-1543.

[24] H. Xiao, F. B. Peters, P. Y. Yang, S. Reed, J. R. Chittuluru, P. G. Schultz, ACS Chem. Biol. 2014, 9, 1092-1096.

[25] L. L. Wan, M. B. Twitchett, L. D. Eltis, A. G. Mauk, M. Smith, Proc. Natl. Acad. Sci. U.S.A. 1998, $95,12825-12831$.

[26] R. Sinclair, S. Hallam, M. Chen, B. Chance, L. Powers, Biochemistry 1996, 35, 15120-15128.

[27] E. L. D'Antonio, J. D'Antonio, V. de Serrano, H. Gracz, M. K. Thompson, R. A. Ghiladi, E. F. Bowden, S. Franzen, Biochemistry 2011, 50, 9664-9680.

[28] B. L. Trumpower, R. B. Gennis, Annu. Rev. Biochem. 1994, 63, 675-716.

[29] S. FergusonMiller, G. T. Babcock, Chem. Rev. 1996, 96, 2889-2907. 
[30] E. Kim, E. E. Chufan, K. Kamaraj, K. D. Karlin, Chem. Rev. 2004, 104, 1077-1133.

[31] X. Liu, Y. Yu, C. Hu, W. Zhang, Y. Lu, J. Wang, Angew. Chem. Int. Ed. 2012, 51, 43124316.

[32] J. A. Sigman, H. K. Kim, X. Zhao, J. R. Carey, Y. Lu, Proc. Natl. Acad. Sci. U.S.A. 2003, $100,3629-3634$.

[33] a) J. Xie, W. Liu, P. G. Schultz, Angew. Chem. Int. Ed. 2007, 46, 9239-9242. b) H. S. Lee, G. Spraggon, P. G. Schultz, F.Wang, J. Am. Chem. Soc. 2009, 131, 2481-2483.

[34] H. S. Lee, P. G. Schultz, J. Am. Chem. Soc. 2008, 130, 13194-13195.

[35] I. Drienovska, A. Rioz-Martinez, A. Draksharapu, G. Roelfes, Chem. Sci. 2015, 6, 770-776.

[36] M. Bersellini, G. Roelfes, Org. Biomol. Chem. 2017, 15, 3069-3073.

[37] I. Drienovska, L. Alonso-Cotchico, P. Vidossich, A. Lledos, J. D. Marechal, G. Roelfes, Chem. Sci. 2017, 8, 7228-7235.

[38] N. Ségaud, I. Drienovská, J. Chen, W. R. Browne, G. Roelfes, Inorg. Chem. 2017, 56, 1329313299.

[39] F. Gan, R. Liu, F. Wang, P. G. Schulz, J. Am. Chem. Soc. 2018, 140, 3829-3832.

[40] J. H. Mills, S. D. Khare, J. M. Bolduc, F. Forouhar, V. K. Mulligan, S. Lew, J. Seetharaman, L. Tong, B. L. Stoddard, D. Baker, J. Am. Chem. Soc. 2013, 135, 13393-13399.

[41] J. H. Mills, W. Sheffler, M. E. Ener, P. J. Almhjell, G. Oberdorfer, J. H. Pereira, F. Parmeggiani, B. Sankaran, P. H. Zwart, D. Baker, Proc. Natl. Acad. Sci. U.S.A. 2016, 113, 15012-15017. 
TOC:

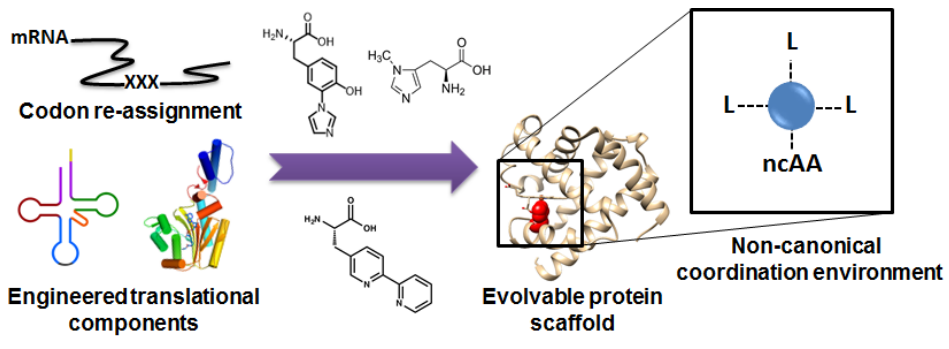

